\title{
Über die Spaltung des Tabakmosaikvirus und die Wiedervereinigung der Spaltstücke zu höhermolekularen Proteinen
}

\section{Versuche zur Wiedervereinigung der Spaltstücke}

\author{
Von Gerhard Schramm \\ Aus dem Kaiser-Wilhelm-Institut für Biochemie, Abtlg. für Virusforschung, Tübingen \\ (Z. Naturforschg. 2/b, 249-257 [1947]; eingegangen am 23. Dezember 1946)
}

\begin{abstract}
Die Spaltprodukte des Tabakmosaikvirus lassen sich wieder zu höhermolekularen Proteinen vereinigen. Mit steigender H-Ionen-Konzentration ändert sich sprunghaft die Größe der Aggregate. Es wurden Versuche mit den verschiedenen Spaltproteinen angestellt. Aus dem kleinsten nucleinsäurefreien Bruchstück (Mol.-Gew. 120000) entsteht zunächst ein sehr einheitliches Polymerisat mit dem dreifachen Molekulargewicht durch lineare Anlagerung. Bei höherer H-Ionen-Konzentration entstehen vier weitere Polymerisationsstufen, z. Tl. nebeneinander, die nicht sehr einheitlich sind. Das bei $p_{\mathrm{H}} 6,5$ auftretende Aggregat ist in der Größe und Gestalt dem ursprünglichen Virus sehr ähnlich. Mit dem nucleinsäurehaltigen Bruchstück vom Molekulargewicht 360000 werden die gleichen Aggregationsstufen erhalten. Das Spaltprotein vom Mol.-Gew. 7000000 aggregiert zunächst einheitlich zu Doppelmolekülen, aus denen wieder höhere Polymerisate gebildet werden können, die nicht einheitlich sind.

Es gelingt nicht, durch die Wiedervereinigung der Bruchstücke die Aktivität des ursprünglichen Virus wiederherzustellen.

Die Frage nach der Ursache der hier vorliegenden auswählenden Polymerisation wird erörtert und die Bedeutung der Versuche für die biologische Entstehung des Virus diskutiert.
\end{abstract}

$I^{n}$ m ersten Teil dieser Arbeit ${ }^{1}$ wurde über die Eigenschaften der beim Zerfall des Tabakmosaikvirus (TMV) auftretenden Spaltkomponenten berichtet. Es war bereits früher beobachtet worden ${ }^{2}$, daß bestimmte Bruchstücke, nämlich die nucleinsäurefreien und die nucleinsäurehaltigen Komponenten vom Molekulargewicht 360000 , wieder zu einem physiologisch inaktiven Protein zusammentreten können; das in seiner Größe und Gestalt dem $T M V$ sehr ähnlich ist. Diese Reaktion wurde seitdem näher untersucht; die auftretenden Zwischenstufen charakterisiert und die Resynthese auch mit einigen der neu aufgefundenen Spaltkomponenten versucht.

1. Versuche mit dem nucleinsäurefreien Protein vom Mol.-Gew. 120000

Es sollen zunächst einige Versuche mit dem kleinsten bisher aufgefundenen nucleinsäurefreien Spaltstück mit der Sedimentationskonstante $s_{20}=5$ (Mol.-Gew. 120000) besprochen werden. Wird die
Lösung dieses Proteins bei verschiedenem $p_{\mathrm{H}}$ in der Ultrazentrifuge untersucht, so zeigt sich, daß die Sedimentationskonstante des Proteins mit steigender H-Ionenkonzentration sprunghaft größer wird. Es entstehen also höhermolekulare Proteine. Im Gegensatz zu der langsam verlaufenden Zerfallsreaktion geht die Aggregation sehr rasch vor sich, wie man aus dem sich momentan ändernden Tyndall-Effekt schließen kann. Bei den Versuchen werden die $p_{\mathrm{H}^{-}}$Werte meistens durch Dialyse gegen die entsprechende Pufferlösung eingestellt, die sich hiernach ergebenden Sedimentationskonstanten sind in Tab. 1 wiedergegeben. Überraschend leicht und sehr einheitlich verläuft der Übergang der Komponente $s_{20}=5$ zu dem dreimal größeren Spaltstück mit $s_{20}=8,7$ (Mittelwert). Diese Synthese gelingt bereits allein durch Erhöhung der Elektrolytkonzentration ohne Veränderung des $p_{\mathrm{H}}$, wie der Vergleich der Versuche $1-5$ zeigt. Bei weiterer Erniedrigung des

1 G. S c h r a m m, Z. Naturforschg. 2 b, 112 [1947].

2 G. Schramm, Naturwiss. 31, 94 [1943]. 


\begin{tabular}{|c|c|c|c|c|c|c|c|c|c|c|}
\hline \multirow{2}{*}{$\begin{array}{l}\text { Vers } \\
\text { Nr. }\end{array}$} & \multirow{2}{*}{$\begin{array}{l}\text { Prä- } \\
\text { pa- } \\
\text { rat }\end{array}$} & \multirow{2}{*}{ 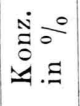 } & \multirow{2}{*}{ Puffer } & \multirow[b]{2}{*}{$p_{\mathrm{H}}$} & \multicolumn{6}{|c|}{ Sedimentationskonstante } \\
\hline & & & & & 1. & 2. & 3. & 4. & 5. & 6. \\
\hline 1 & 394 & 0,1 & $\begin{array}{c}m / 100- \\
\text { Glykokoll }\end{array}$ & 9,7 & 4,7 & - & - & 一 & - & - \\
\hline 2 & 405 & 0,16 & $\begin{array}{c}m / 100- \\
\text { Glykokoll }\end{array}$ & 9,6 & 4,7 & - & - & 一 & - & - \\
\hline 3 & 405 & 0,16 & $\begin{array}{c}m / 100- \\
\mathrm{NaHCO}_{3}\end{array}$ & 9,3 & 5,2 & + & - & 一 & - & - \\
\hline 4 & 405 & 0,16 & $\begin{array}{c}m / 10- \\
\text { Glykokoll }\end{array}$ & 9,5 & + & 9,0 & - & 一 & - & - \\
\hline 5 & 403 & 0,4 & $\begin{array}{c}m / 10- \\
\mathrm{NaHCO}_{3}\end{array}$ & 9,4 & - & 8,7 & - & - & - & - \\
\hline 6 & 394 & 0,2 & $\begin{array}{c}m / 10- \\
\text { Phosphat }\end{array}$ & 6,9 & - & 8,4 & 31 & 一 & - & - \\
\hline 7 & 409 & 0,17 & $\begin{array}{c}m / 10- \\
\text { Phosphat }\end{array}$ & $6, \mathbf{5}$ & - & - & 48 & 185 & - & - \\
\hline 8 & 40. & 0,16 & $\begin{array}{c}m / 10- \\
\text { Phosphat }\end{array}$ & 6,5 & - & - & - & 168 & - & - \\
\hline 9 & 409 & 0,166 & $\begin{array}{c}m / 10- \\
\text { Phosphat }\end{array}$ & 6,5 & - & - & - & $?$ & 206 & - \\
\hline 10 & 403 & 0,1 & $\begin{array}{r}m / \\
\text { Phos }\end{array}$ & 6,0 & - & - & - & 169 & ? & 557 \\
\hline 11 & 394 & 0,2 & $\begin{array}{c}m / 10- \\
\text { Phosphat }\end{array}$ & 5,8 & $\cdots$ & - & - & + & 220 & 416 \\
\hline 12 & 403 & 0,1 & $\begin{array}{c}m / 10- \\
\text { Phosphat }\end{array}$ & 5,0 & - & - & - & - & - & 507 \\
\hline & & & $w$ & 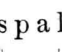 & & & & & & \\
\hline W 1 & 403 & 0,09 & $\begin{array}{r}m / 1 \\
\text { Glyke }\end{array}$ & 9,3 & - & - & + & 93 & - & - \\
\hline W 2 & 403 & 0,09 & $\begin{array}{r}m / 1 \\
\text { Glyk }\end{array}$ & 9,5 & - & - & 46 & 117 & - & - \\
\hline
\end{tabular}

Tab. 1. Synthese-Versuche mit Spaltkomponente

$$
s_{20}=5,0 \text {. }
$$

+ Komponente vorhanden, aber nicht gemessen. - Komponente nicht vorhanden. ? Vorkommen unsicher.

a) Die Versuche wurden mit dem Aggregationsprodukt von Vers. 12 durchgeführt.

$p_{\mathrm{H}}$ entsteht aus dieser Komponente ein Protein mit einer stark konzentrationsabhängigen Sedimentationskonstante von ungefähr 169. In einigen Fällen konnte hierbei in geringer Menge eine Zwischenstufe mit $s_{20} \sim 40$ beobachtet werden (Vers. Nr. 6 u. 7). .Wird die Lösung noch stärker angesäuert, so treten noch höhere Aggregationsprodukte auf, deren Sedimentationskonstanten wohl ebenfalls wegen ihrer Konzentrationsabhängigkeit etwas schwankend sind (Versuch 10-12). Um den Einfluß der Salzkonzentration zu untersuchen, wurden auch einige Versuche in sehr verdünnter Pufferlösung $(\mathrm{m} / 1000$-Acetat) durchgeführt (Tab.2). Es ergab sich aber hierbei kein grundsätzlicher Unterschied. Nur muß das $p_{\mathrm{H}}$ bei

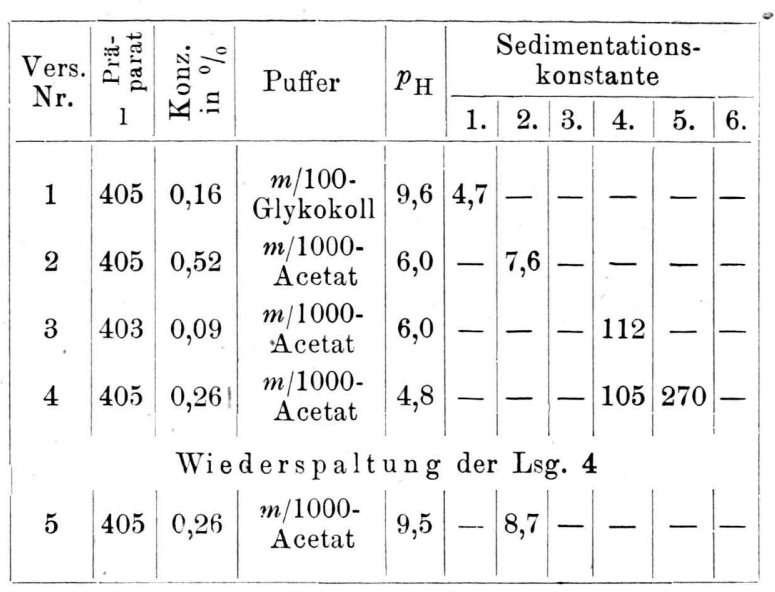

Tab. 2. Synthese-Versuche in $m / 1000$-Acetat mit Spaltkomponente $s_{20}=5,0$.

dieser geringen Salzkonzentration höher gewählt werden, um die gleiche Aggregationsstufe zu erhalten.

Über die Einheitlichkeit der entstehenden Aggregate geben die Sedimentationsdiagramme Abb.1 bis 5 nähere Aufschlüsse. Auf der 1 . Abb. ist zunächst das Sedimentationsdiagramm des Ausgangsstoffes wiedergegeben. Infolge der hohen Diffusionskonstanten und der langen Zentrifugierungszeit ist der Gipfel ziemlich breit. Wird diese Lösung angesäuert bzw. gegen einen Puffer mit geringerem $p_{\mathrm{H}}$ dialysiert, so erhalten wir ein vollständig einheitliches Protein mit dreimal so hohem Molekulargewicht (Abb.2). Gleichscharfe Gradienten erhielten wir, wenn die Aggregation nicht

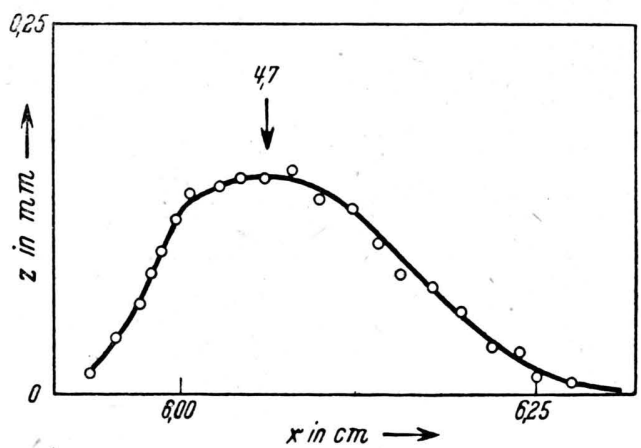

Abb.1. Sedimentationsdiagramm der nucleinsäurefreien Komponente $s_{20}=5$, Mol.-Gew. $=120000, c=0,16 \%$, Skalenabstand $=8 \mathrm{~cm}$, Drehzahl $=39000 \mathrm{U} / \mathrm{min}$, $z=$ Skalenstrichverschiebung, $x=$ Abstand vom Rotationszentrum. Die Entfernung des Meniskus der Lösung vom Rotationszentrum beträgt bei allen Versuchen 5,81 cm. Die Pfeile geben den 50\%-Punkt der Konzentration an, die dazugehörige Zahl die gemes. sene Sedimentationskonstante. 
dem des $T M V$ liegt, für das (bei $c=0$ ) $s_{20}=198$ Svedberg ${ }^{3}$ gefunden wurde. Der Verlauf der Kurve bei höheren Konzentrationen ist allerdings etwas verschieden, da die Änderung der Sedimentationskonstante mit der Konzentration bei dem synthetischen Protein stärker ist als beim TMV.

Das bei der Synthese entstehende Protein hat nicht nur die gleiche Sedimentationskonstante wie das Virus, sondern muß auch eine ähnliche Gestalt besitzen. Ein wichtiges Argument hierfür ist die Tatsache, daß das synthetische Produkt in ganz ähnlicher Form kristallisiert wie das Virus. Fälit man bei $p_{\mathrm{H}}$ 4,8 mit Ammonsulfat, so erhält man in beiden Fällen parakristalline Nadeln.

Zur Darstellung der Kristalle werden etwa $50 \mathrm{mg}$ des elektrophoretisch dargestellten nucleinsäurefreien Proteins gegen $m / 10$-Phosphat vom $p_{\mathrm{H}} 8$ dialysiert. Dann wird durch Zugabe des gleichen Volumens gesättigter Ammonsulfatlösung gefällt und der Niederschlag in $2 \mathrm{ccm} m / 10$-Phosphat $\left(p_{\mathrm{H}} 7\right)$ aufgenommen. Unlösliche Flocken werden abzentrifugiert, die überstehende klare Lösung mit 1-n. Essigsäure auf $p_{\mathrm{H}} 4,8$ gebracht und tropfenweise mit gesättigter Ammonsulfatlösung bis zur beginnenden Trübung versetzt. Es bilden sich sofort kristalline Nadeln, die im Mikroskop das gleiche Aussehen zeigen wie die Kristalle des Virus, mitunter jedoch etwas kleiner sind.

Um die Übereinstimmung zwischen synthetischem und natürlichem Protein weiter zu prüfen, haben wir das Molekulargewicht und die Formfaktoren eines synthetischen Proteins mit dem eines polymerisierten Virus unter ähnlichen Bedingungen verglichen. Es handelt sich hierbei um ein Polymerisat aus einem älteren Viruspräparat, über dessen Darstellung in anderem Zusammenhang bereits berichtet wurde ${ }^{3}$. Tab. 3 zeigt, daß nicht nur die mittleren Molekulargewichte recht gut übereinstimmen, sondern auch die Reibungskoeffizienten von gleicher Größenordnung sind. Das hier gemessene Aggregationsprodukt entspricht in seiner Größe und Gestalt etwa einem trimeren $T M V$. Der hohe Wert von $f: f_{0}$ beweist, daß das synthetische Protein, ebenso wie das Virus selbst, eine stark asymmetrische stäbchenförmige Gestalt besitzen muß.

Diese Molekülform wurde auch unmittelbar durch elektronenmikroskopische Aufnahmen sichtbar gemacht, die früher veröffentlicht wurden ${ }^{2}$. Allerdings ergibt sich auch hier wieder ein gewisser Unterschiẹ gegenüber den ursprünglichẻn Virusteilchen. Die Konturen sind bei dem synthe-

3 G. Schramm u. G. Bergold, Z. Naturforschg. 2 b, 110 [1947].

\begin{tabular}{|c|r|r|r|r|r|c|}
\hline & $C$ & $s_{20}$ & $D_{20}$ & $M$ & $f / f_{0}$ & $L / d$ \\
\hline \begin{tabular}{c|c|c|c|c|c|} 
Polymeres TMV \\
$\begin{array}{c}\text { Polymerisat aus } \\
\boldsymbol{s}_{20}=5,0\end{array}$
\end{tabular} & 0,2 & 218 & 0,209 & 99 & 3,32 & 65 \\
$\begin{array}{c}\text { Ber.für trimeres } \\
\text { TMV }\end{array}$ & 206 & 0,173 & 113 & 3,84 & 90 \\
\hline
\end{tabular}

Tab. 3. Vergleich eines polymeren $T M V$ mit dem Polymerisat aus $s_{\mathbf{2 0}}=5$. Die Messungen wurden in $0,1-m$. Phosphat durchgeführt. $C=$ Konzentration , $D_{20}=$ Diffusionskonstante, $M=$ Mol.-Gew., $f / f_{0}=$ Reibungsverhältnis, $L / d=$ Länge : Dicke.

tischen Produkt unscharf und es ist schwer, eine für die Reproduktion geeignete Aufnahme zu erhalten. Auf den Kontrollạufnahmen des niedrigmolekularen Ausgangsmaterials sind stäbchenförmige Teilchen niemals sichtbar geworden. $\mathrm{Ob}$ die auf dem früher veröffentlichten Bild sichtbaren Pünktchen allerdings dem niedrigmolekularen Protein entsprechen, erscheint heute zweifelhaft. Die Versuche sollen wiederholt werden, sobald hierfür die Möglichkeiten gegeben sind.

Zusammenfassend läßt sich feststellen, daß trotz aller Ähnlichkeit die Übereinstimmung zwischen dem nucleinsäurefreien synthetischen Protein und dem Virus doch nicht vollständig ist. Am auffallendsten ist wohl der Unterschied in der Einheitlichkeit dieser Proteine. In der ersten Mitteilung ${ }^{2}$ (1943) konnte keine genaue Aussage über die Homogenität des synthetischen Proteins gemacht werden, da zur Beobachtung der Sedimentation nur die Toeplersche Schlierenmethode zur Verfügung stand. Mit dieser Anordnung konnten wir damals keinen deutlichen Unterschied gegenüber dem Originalvirus feststellen. Dieser Schluß ist auch heute noch in gewisser Beziehung berechtigt, da das $T M V$ unter den damals angewendeten Bedingungen recht uneinheitlich ist, besonders wenn es sich um ältere Präparate handelt. Vergleichen wir aber das Sedimentationsdiagramm des synthetischen Proteins $s_{20}=195$ $(c=0)$ mit dem einer einwandfreien Viruslösung, so ist zweifellos das synthetische Protein sehr viel uneinheitlicher.

Das synthetische Protein scheint auch in seiner inneren Struktur nicht ganz dem TMV zu entsprechen. Dies zeigt sich bei dem Versuch, es wieder in seine Grundeinheiten zu zerlegen. Die Beständigkeit gegenüber der Einwirkung der Hydroxylionen scheint bei den in Phosphat aggre- 
gierten Produkten etwas größer zu sein als bei den in $m / 1000$-Acetat erbaltenen (siehe Tab. $1 \mathrm{u}$. 2, Wiederspaltung). Soweit sich bisher feststellen ließ, treten in keinem Falle die bei der Virusspaltung beobachteten Bruchstücke auf. Ziemlich regelmäßig finden wir dagegen bei der Wiederspaltung eine Komponente mit $s_{20} \sim 40$ (siehe Tab. 1, Vers. W 2), die bei der Spaltung des Virusmoleküls nicht beobachtet wurde.

Ein wichtiger Unterschied gegenüber den Originalvirus ist ferner das Fehlen der Vermehrungsfähigkeit bei dem Aggregationsprodukt. Diese ist allerdings in dem bisher besprochenen Fall kaum zu erwarten, da ja die Nucleinsäure fehlt.

2. Aggregationsversuche mit den nucleinsäurehaltigen Spaltkompo$n$ enten

In derselben Weise wie mit der nucleinsäurefreien Komponente wurde eine Reihe von Sedimentationsmessungen mit dem kleinsten nucleinsäurehaltigen Spaltstück vom Mol.-Gew. 360000 durchgeführt. Tab. 4 zeigt, daß sich hierbei die gleichen Aggregationsstufen ausbilden. Die Sedi-

\begin{tabular}{|c|c|c|c|c|c|c|c|c|}
\hline \multirow{2}{*}{$\begin{array}{l}\text { Vers. } \\
\text { Nr. }\end{array}$} & \multirow{2}{*}{$\begin{array}{c}\text { Präpa- } \\
\text { rat } \\
\text { s }\end{array}$} & \multirow{2}{*}{ 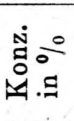 } & \multirow{2}{*}{ Puffer } & \multirow{2}{*}{$p_{\mathrm{H}}$} & \multicolumn{4}{|c|}{$\begin{array}{l}\text { Sedimentations- } \\
\text { konstante }\end{array}$} \\
\hline & & & & & 1. & 2. & 3. & 4. \\
\hline 1 & 401 & 0,3 & $\begin{array}{c}m / 100- \\
\text { Glykokoll }\end{array}$ & 9,6 & 9,4 & - & - & - \\
\hline 2 & 386 & 0,47 & $\begin{array}{c}m / 100- \\
\text { Glykokoll }\end{array}$ & 9 & 9,0 & - & - & - \\
\hline 3 & 268 & 0,35 & $\begin{array}{c}m / 10- \\
\text { Phosphat }\end{array}$ & 7,8 & 8,5 & - & - & - \\
\hline 4 & 273 & 0,7 & $\begin{array}{c}m / 100- \\
\text { Glykokoll }\end{array}$ & 7 & - & 39 & 91 & - \\
\hline 5 & 386 & 0,47 & $\begin{array}{c}m / 10- \\
\text { Phosphat }\end{array}$ & 7,0 & - & - & 124 & - \\
\hline 6 & 386 & 0,47 & $\begin{array}{c}m / 10- \\
\text { Phosphat }\end{array}$ & 6,8 & - & - & 118 & - \\
\hline 7 & 386 & 0,47 & $\begin{array}{l}m / 10- \\
\text { Acetat }\end{array}$ & 5,9 & - & - & 115 & - \\
\hline 8 & 386 & 0,47 & $\begin{array}{l}m / 10- \\
\text { Acetat }\end{array}$ & 6,1 & - & - & 121 & - \\
\hline 9 & 386 & 0,47 & $\begin{array}{c}m / 10- \\
\text { Phosphat }\end{array}$ & 6,1 & - & - & 139 & - \\
\hline 10 & 386 & 0,47 & $\begin{array}{l}m / 10- \\
\text { Acetat }\end{array}$ & 5,0 & - & $?$ & 189 & 345 \\
\hline
\end{tabular}

Tab. 4. Synthese-Versuche mit Nucleoproteid $s_{20}=8,7$ (Mol.-Gew. 360000). Die Versuche wurden z.Tl. mit der Schlierenmethode beobachtet, so daß uns möglicherweise in einigen Fällen Komponenten, die in geringer Konzentration anwesend waren, entgangen sind. mentationskonstante der bei $p_{\mathrm{H}} 6,5$ auftretenden Komponente konnte auf $c=0$ extrapoliert werden (Abb.6). Es ergab sich ebenfalls ein Wert, der nahe bei dem des TMV liegt. Auch die Einheitlichkeit der gebildeten Proteine unterscheidet sich in keiner Weise von den entsprechenden nucleinsäurefreien Eiweißstoffen. Auf eine Wiedergabe der Sedimentationsdiagramme kann daher verzichtet werden.

Der gleichartige Verlauf der Aggregationen gestattet gewisse Rückschlüsse auf die Funktion der Nucleinsäure im Virusmolekül zu ziehen. Da mit und ohne Nucleinsäure die gleichen Aggregationsstufen ausgebildet werden, ist anzunehmen, daß diese für den Zusammenhalt der Teilchen im Virusmolekül nicht von maßgebender Bedeutung ist, wahrscheinlich ist sie an der Oberfläche des Moleküls angeordnet.

Es war zu hoffen, daß bei Verwendung der größeren Spaltstücke ein einheitlicheres Endprodukt entstehen würde als bei Verwendung niedrigmolekularer Bruchstücke, da hier die Kombinationsmöglichkeiten beschränkter sind.

Da von den höheren Spaltstücken nur das Nucleoproteid mit $s_{20}=97$ (Mol.-Gew. 7000000) in annähernd reiner Form isoliert werden kánn, haben wir uns hauptsächlich mit diesem beschäftigt. Es ergeben sich hierbei recht ähnliche Verhältnisse wie bei dem nucleinsäurefreien Bruchstück mit dem Mol.-Gew. 120000. Der erste Aggregationsschritt zur nächsthöheren Stufe verläuft nämlich wieder außerordentlich glatt und einheitlich. Es handelt sich in diesem Fall um eine Verdoppelung des Molekulargewichtes. Wiederum genügt bereits eine Erhöhung der. Salzkonzentration, um die Vereinigung zu bewirken. Diese Versuche sind in Tab. 5 zusammengestellt.

\begin{tabular}{|c|c|c|c|c|c|c|c|}
\hline \multirow{2}{*}{$\begin{array}{c}\text { Vers. } \\
\text { Nr. }\end{array}$} & \multirow{2}{*}{ Puffer } & \multirow{2}{*}{$p_{\mathrm{H}}$} & \multicolumn{5}{|c|}{ Sedimentationskonstante } \\
\hline & & & 1. & 2. & 3. & 4. & 5. \\
\hline 1 & $m / 50-$ Veronal & 7,9 & 92 & + & (134) & (147) & - \\
\hline 2 & $m / 10$-Phosphat & 8,4 & 96,5 & 125 & $(129)$ & + & - \\
\hline 3 & $m / 10-\mathrm{NaHCO}_{3}$ & 8,1 & + & 122 & $(132)$ & + & - \\
\hline 4 & $m / 10$-Phosphat & 6,9 & + & 128 & + & + & - \\
\hline 5 & $m / 10$-Phosphat & 5,7 & - & - & - & - & 212 \\
\hline
\end{tabular}

Tab. 5. Synthese-Versuche mit Spaltkomponente $s_{20}=97, c=0,22 \%$. Die eingeklammerten Werte beziehen sich auf Komponenten, die nur in Spuren vorhanden waren. Siehe hierzu die entsprechenden Sedimentationsdiagramme. 


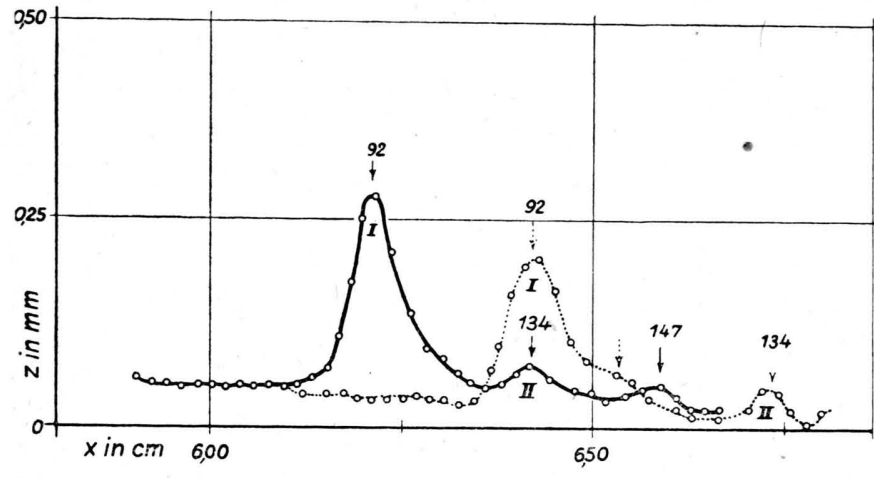

Abb. 7. Spaltprotein $s_{20}, c_{20}=97$ in $0,02-m$. Veronalpuffer $\left(p_{\mathrm{H}} 7,9\right) . c=0,22 \%$, Skalenabstand $7 \mathrm{~cm}$, $25400 \mathrm{U} / \mathrm{min}$. Zeitraum zwischen den beiden Aufnahmen $10 \mathrm{~min}$.

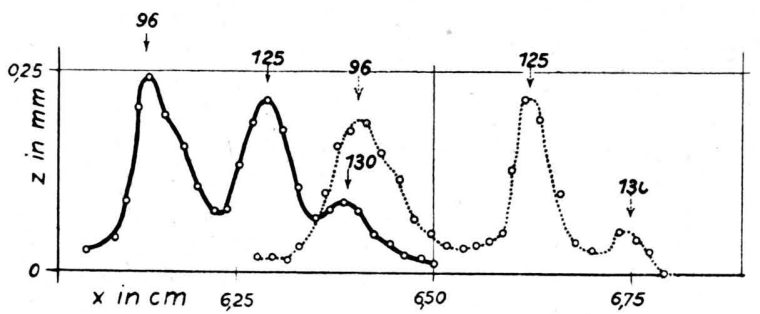

Abb. 8. Gleiche Lösung wie in Abb. 7 nach Dialyse gegen $0,1-m$. Phosphat $\left(p_{\mathrm{H}} 8,4\right) . c=0,22 \%$, Skalenabstand $10 \mathrm{~cm}, 25000 \mathrm{U} / \mathrm{min}$. Zeitraum zwischen den beiden Aufnahmen $10 \mathrm{~min}$.

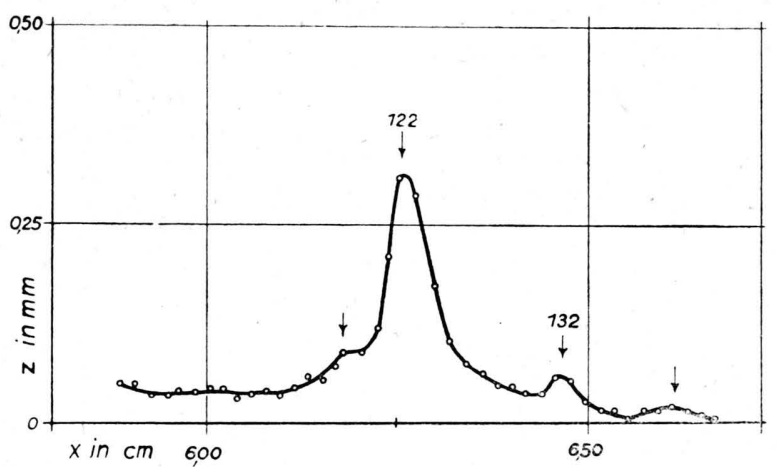

Abb. 9. Gleiche Lösung wie in Abb. 7 und 8 nach Dialyse gegen $0,1-m . \mathrm{NaHCO}_{3}\left(p_{\mathrm{H}} 8,1\right) . c=0,22 \%$, Skalenabstand $6 \mathrm{~cm}, 20000 \mathrm{U} / \mathrm{min}$.

Der überraschend einheitliche Verlauf der Synthese wird durch die Abb. 7-9 veranschaulicht. Auf Abb. 7 sehen wir im wesentlichen nur die Ausgangskomponente neben geringen Verunreinigungen durch drei höhere Spaltkomponenten. Nach Erhöhung der Salzkonzentration tritt dann der neue Gipfel auf, der dem Doppelmolekül entspricht (Mol.-Gew. 14,8·106; Abb. 8). Dessen
Konzentration nimmt bei Erniedrigung des $p_{\mathrm{H}}$ weiter zu, während dịe Ausgangskomponente nahezu vollständig verschwindet (Abb. 9). Erhöhen wir die H-Ionenkonzentration weiter, so aggregiert das DoppelmoleküI $s_{20}=125$ wieder zu dem gleichen uneinheitlichen Protein, wie es aus den kleineren Bruchstücken erhalten wurde.

Ähnliche Aggregationsversuche wurden auch mit einer Lösung angestellt, die neben der unveränderten Ausgangskomponente im wesentlichen aus der ersten 5/6-Spaltstufe (Mol.-Gew. 34 Millionen) bestand. Das Sedimentationsdiagramm ist wiedergegeben in Abb. 4 des ersten Teils dieser Untersuchung ${ }^{1}$. Wird diese Lösung durch Dialyse gegen 0,1-m. Phosphat auf $p_{\mathrm{H}} 6,5$ gebracht, so erhält man wieder das Diagramm eines uneinheitlichen Proteins mit $s_{20}=191$. Es ist in diesem Falle schwierig, die Uneinheitlichkeit zu erklären, da die Möglichkeit zu Zwischenstufen zwiI schen dem 5/6 und dem ganzen Molekül eigentlich nicht gegeben ist. Es bieten sich zwei Möglichkeiten der Erklärung: 1. Die ganzen und die 5/6-Moleküle reagieren kurzzeitig miteinander, so daß im Zeitmittel ein Gemisch verschiedener Molekülgrößen vorgetäuscht wird. 2. Die in der Lösung ebenfalls noch vorhandenen niederen Spaltkomponenten lagern sich an die beiden Hauptkomponenten an, so daß sich hierdurch eine tatsächliche Streuung der Molekülgröße ergibt.

Dieser letzten Erklärung möchten wir den Vorzug geben, da wir beobachtet haben, daß auch das ungespaltene Virusmolekül in Gegenwart sehr kleiner Mengen niedrigmolekularer Zerfallsprodukte ein uneinheitliches Sedimentationsdiagramm gibt.

Diese letzten Versuche lassen es möglich erscheinen, daß primär ein homogeneres Aggregat entsteht, welches dann sekundär durch Anlagerung überschüssiger kleiner Bruchstücke uneinheitlich wird. Vielleicht gelingt es, durch weitere Versuche diese sekundären Einflüsse auszuschalten.

3. Versuche zur Darstellung eines biologisch-aktiven Proteins aus den Spaltstücken

Nachdem sich gezeigt hatte, daß sich die Spaltstücke zu einem dem Virus chemisch und physikalisch sehr ähnlichen Protein zusammenfügen lassen, erschien es nicht ausgeschlossen, auch die biologische Aktivität wieder herzustellen. Es wur- 
den daher in Zusammenarbeit mit G. Melchers (Kaiser-Wilhelm-Institut für Biologie) eine Reihe von Versuchen in dieser Richtung angestellt. Zum Vergleich der biologischen Aktivität der verschiedenen Präparate wurde der bekannte Einzelherdtest von $\mathrm{H}$ ol me $\mathrm{s}^{4}$ benutzt. Dieser beruht darauf, daß das $T M V$ auf den Blättern bestimmter Pflanzen wie Nicotiana glutinosa, Phaseolus vulgaris oder Datura stramonium keine Allgemeininfektion, sondern lokalisierte Einzelnekrosen erzeugt. Um einen Vergleich durchzuführen, wird auf der einen Blatthälfte die Versuchslösung, auf der anderen die Kontroll-Lösung mit einem Mulltupfer aufgetragen. Durch Auszählen der gebildeten Nekrosen auf jeder Blatthälfte erhält man dann ein Maß für die relative Wirksamkeit der Präparate.

Wie bereits früher mitgeteilt wurde ${ }^{2}$, besitzen die Aggregate aus dem kleinsten Nucleoproteid keine Viruswirksamkeit. Dies scheint uns heute nicht mehr verwunderlich, nachdem wir festgestellt haben, daß unter dem Einfluß von $\mathrm{OH}$ Ionen bereits eine Inaktivierung des Virus erfolgt, bevor sich das Molekulargewicht merklich ändert (siehe hierzu den 1. Teil dieser Untersuchung). Es genügt also nicht, die ursprüngliche Molekülform des Virus wieder herzustellen, wenn nicht gleichzeitig diese erste Alkaliwirkung rückgängig gemacht werden kann.

Es fragt sich nun, worin diese Inaktivierung besteht. Versuche, das inaktive unzerfallene Virus durch einfache Dialyse gegen saure Pufferlösungen, z. B. $0,1-m . \mathrm{KH}_{2} \mathrm{PO}_{4}$ vom $p_{\mathrm{H}} 4,8$, wieder zu reaktivieren, schlugen fehl. Ebensowenig gelang es, durch starke Reduktionsmittel wie Hypophosphit oder Hydrosulfit die Inaktivierung rückgängig zu machen (Tab.6).

Eine naheliegende Annahme war daher, daß in der alkalischen Lösung aus dem Virus ein niedrigmolekularer Bestandteil, z. B. ein Metallion oder eine Wirkgruppe, abgespalten wird. $\mathrm{Zu}$ diesem Zweck wurde eine Mischung der Spaltproteine, die z.Tl. noch unzerfallene Moleküle enthielt, in Gegenwart verschiedener, in Proteinen vorkommender Kationen durch Erniedrigung des $p_{\mathrm{H}^{-}}$Wertes reaggregiert. Wie Tab. 6 zeigt, wurden folgende Metallionen geprüft: $\mathrm{Mg}$ *, $\mathrm{Mn}$ “, $\mathrm{Zn}$ *, $\mathrm{Cu}{ }^{*}, \mathrm{Fe}$. Außerdem wurde auch die Kombination einer Reduktionswirkung durch Cystein mit Zugabe von Mg-Ionen (0,1-m.) bei verschiedenem

${ }^{4}$ F. O. Holmes, Bot. Gaz. 87, 39 [1929].

\begin{tabular}{|c|c|c|c|c|}
\hline \multirow{2}{*}{$\begin{array}{l}\text { Vers. } \\
\text { Nr. }\end{array}$} & \multirow{2}{*}{$\begin{array}{l}\text { Zusatz } \\
\text { Konz.: 0,1-m. }\end{array}$} & \multirow{2}{*}{$\begin{array}{c}p_{\mathrm{H}} \\
\text { der } \\
\text { Aggre- } \\
\text { gat. }\end{array}$} & \multicolumn{2}{|c|}{$\begin{array}{l}\text { Zahl der Einzelherde } \\
\text { je } 100 \text { Blatthälften }\end{array}$} \\
\hline & & & ohneZusatz & mit Zusatz \\
\hline 1 & Hypophosphit & 4,2 & 1 & 2 \\
\hline 2 & Hydrosulfit. & 4,2 & 4 & 3 \\
\hline 3 & $\mathrm{Zn} \cdot \ldots$ & 4,2 & 3 & 3 \\
\hline 4 & $\mathrm{Mn} \cdots \ldots$ & 4,2 & 4 & 2 \\
\hline 5 & $\mathrm{Cu}{ }^{\prime} \ldots \ldots$ & 4,2 & 0 & 1 \\
\hline 6 & $\mathrm{Fe}{ }^{\prime} \ldots . .$. & 4,2 & 2 & 1 \\
\hline 7 & $\mathrm{Mg}^{*} \ldots \ldots$ & 4,2 & 5 & 1 \\
\hline 8 & Mg " u. Cystein & 4,8 & 10 & 5 \\
\hline 9 & Mg u. Cystein & 3,5 & 7 & 5 \\
\hline
\end{tabular}

Tab. 6. Versuche zur Aktivierung des Tabakmosaikvirus durch verschiedene Zusätze. Jeder Versuch wurde an 20 Nicotiana-glutinosa-Pflanzen zu je 5 Blätter durchgeführt. Die Viruskonzentration betrug bei der Auswertung $1^{-\mathbf{5}} \mathrm{g}$ Protein/ccm.

$p_{\mathrm{H}}$ untersucht. Wie Tab. 6 zeigt, führte keiner der Versuche zu einer deutlichen Erhöhung der Aktivität gegenüber den unbehandelten Kontrollen.

Auf Grund unserer Hypothese mußte es weiterhin aussichtsreich erscheinen, aus einer gröBeren Virusmenge durch Alkali die Nucleinsäure und alle evtl. vorhandenen Wirkgruppen abzuspalten und diese zu einer kleinen Menge vorsichtig inaktivierten Virus' zu geben. Hierbei wurden variiert: 1. die Art der Inaktivierung (vorsichtige Spaltung mit Glykokoll-, Borat- oder $\mathrm{NaHCO}_{3}$-Puffer bei verschiedenem $p_{\mathrm{H}}$ ), 2. der $p_{\mathrm{H}^{-}}$Wert der Reaggregation und 3. die Art der Versuchspflanzen, da möglicherweise das reaktivierte Virus andere biologische Eigenschaften haben konnte als die Ausgangsform. Bei einem Versuch wurde außerdem Preß-Saft aus gesunden Tabakpflanzen zugefügt, um durch ein evtl. vorhandenes Enzym die Anlagerung einer Wirkgruppe zu katalysieren.

Das Ergebnis dieser Versuche ist in Tab. 7 zusammengefaßt. Bei den ersten drei Versuchen wurde zwar eine geringe Erhöhung der Aktivität beobachtet, doch ist diese nicht als reell anzusehen, da sie bei den späteren Versuchen nicht reproduzierbar war. Bei den Versuchen 5 und 8 ist eine deutliche Erhöhung der Aktivität zu bemèrken, die auch statistisch gesichert ist. Dies ist aber darauf zurückzuführen, daß die zugesetzte $A$-Lösung noch aktives Virus enthielt. Aus den Versuchen geht also hervor, daß es bisher nicht mit Sicherheit gelungen ist, eine größere Virusmenge zu reaktivieren. Die Bildung einzelner vermehrungsfähiger Moleküle kann jedoch bei der 


\begin{tabular}{|c|c|c|c|c|c|c|c|c|c|c|}
\hline \multirow{2}{*}{$\begin{array}{l}\text { Vers. } \\
\text { Nr. }\end{array}$} & \multirow{2}{*}{$\begin{array}{l}\text { Aus- } \\
\text { gangs- } \\
\text { losung }\end{array}$} & \multicolumn{2}{|c|}{$\begin{array}{c}\text { Inaktivierung } \\
\text { durch }\end{array}$} & \multirow{2}{*}{$\begin{array}{l}\text { Zusatz- } \\
\text { lösung }\end{array}$} & \multirow{2}{*}{$\begin{array}{c}p_{\mathrm{H}} \text { der } \\
\text { Aggre- } \\
\text { gat. }\end{array}$} & \multirow{2}{*}{ Testpflanze } & \multirow{2}{*}{$\begin{array}{c}\text { Zahl } \\
\text { der } \\
\text { Test- } \\
\text { blätter }\end{array}$} & \multicolumn{2}{|c|}{$\begin{array}{c}\text { Einzelherde je } \\
100 \text { Blatthälften }\end{array}$} & \multirow{2}{*}{ Diff. } \\
\hline & & Puffer & $p_{\mathrm{H}}$ & & & & & $\begin{array}{c}\text { ohne } \\
\text { Zusatz }\end{array}$ & $\begin{array}{c}\text { mit } \\
\text { Zusatz }\end{array}$ & \\
\hline 1 & $Z$ III & Glykokoll & 10,5 & $A \mathrm{I}$ & 4,2 & Dat. stram. & 87 & 3,5 & 26,5 & +23 \\
\hline 2 & $Z$ III & Glykokoll & $.10,5$ & $A \mathrm{I}$ & 6,8 & Dat. stram. & 75 & 1,3 & 2,6 & $\begin{array}{r}20 \\
+\quad 1,3\end{array}$ \\
\hline 3 & $Z$ III & Glykokoll & 10,5 & $A$ II & 3,9 & Nicot. glut. & 47 & 4,3 & 17 & $+12,7$ \\
\hline 4 & $Z$ III & Glykokoll & 10,5 & $A$ II & 4,6 & Nicot. glut. & 95 & 3,2 & 2,2 & \\
\hline 5 & $Z$ IV & Glykokoll & 10,5 & $A$ III & 3,9 & Nicot. glut. & 48 & 39 & 118 & +79 a) \\
\hline 6 & $Z$ IV & Glykokoll & 10,5 & $A \mathrm{~V}$ & 3,9 & Nicot. glut. & 130 & 4,6 & 1,5 & $-\quad 3,1$ \\
\hline 7 & $Z \mathrm{IV}$ & Glykokoll & 10,5 & $A \mathrm{~V}+S^{\mathrm{c}}$ & 3,9 & Nicot. glut. & 130 & 2,3 & 0 & $-\quad 2,3$ \\
\hline 8 & $Z \mathrm{~V}$ & Glykokoll & 10,5 & $A$ III & 3,9 & Nicot. glut. & 49 & 30,6 & 112,2 & $+79^{b}$ \\
\hline 9 & $Z \mathrm{~V}$ & Glykokoll & 10,5 & $\boldsymbol{A} \mathrm{IV}^{\mathrm{d})}$ & 3,9 & Nicot. glut. & 150 & 9,34 & 12,7 & $+\quad 3,4$ \\
\hline 10 & $Z G$ & Glykokoll & 10,0 & $A$ VI & 3,9 & Dat. stram. & 113 & 10,6 & 9,7 & $\begin{array}{l}-\quad 0,9 \\
-\quad 1\end{array}$ \\
\hline 11 & $Z S$ & Soda & 10,0 & $A$ VI & 3,9 & Phas. vulg. & 25 & 144 & 71 & -73 \\
\hline 12 & $Z B$ & Borat & 10,0 & $A$ VI & 3,9 & Phas. vulg. & 20 & 625 & 85 & -540 \\
\hline 13 & $Z G 9,7$ & Glykokoll & 9,7 & $A$ VII & 3,9 & Nicot. glut. & 70 & 365 & 361 & -4 \\
\hline 14 & $Z S 9,7$ & Soda & 9,7 & $A$ VII & 3,9 & Phas. vulg. & 50 & 20 & 16 & -4 \\
\hline 15 & $Z B 9,7$ & Borat & 9,7 & $A$ VII & 3,9 & Phas.vulg. & 50 & 72 & 44 & -28 \\
\hline
\end{tabular}

Tab. 7. Versuche zur Reaktivierung des Tabakmosaikvirus durch Zugabe der alkalischen Abspaltungsprodukte.

a) Die Differenz ist statistisch gesichert. Höchstzulässige Zufallsdifferenz $73^{5}$. b) Die Differenz ist statistisch gesichert. Höchstzulässige Zufallsdifferenz $50,4^{5}$.

c) $S=1 \mathrm{ccm}$ Pflanzensaft.

d) Als Kontrolle diente in diesem Fall eine nicht angesäuerte Mischung der Ausgangslösung und $A \mathrm{IV}$.

Versuchsbedingung: $T M V$ wurde mit verschiedenen Pufferlösungen bei verschiedenem $p_{\mathrm{H}}$ gespalten $(Z$ Lösung). Versuche in der Ultrazentrifuge zeigten, daß die in dieser Weise entstehende Lösung neben niedrigmolekularen Proteinen auch unzerfallene inaktive Virusmoleküle enthielten. Etwa $0,1 \mathrm{mg}$ inaktiviertes Virus wurden mit den Abspaltungsprodukten aus $50 \mathrm{mg}$ Virus ( $A$-Lösung) versetzt und mindestens 12 Stdn. stehen gelassen. Für die Auswertung wurden dann die Ansätze mit $0,1-m$. Phosphat von $p_{\mathrm{H}} 7$ auf $10-5 \mathrm{~g}$ Protein $/ \mathrm{cm}^{3}, \mathrm{bzw}$. bei den ersten vier Versuchen auf $5 \cdot 10^{-6}$ g Protein $/ \mathrm{cm}^{3}$ verdünnt. Die $A$-Lösungen wurden bei $p_{\mathrm{H}} 12,5$ gew onnen. Bei diesem $p_{\mathrm{H}}$ fällt das Protein in denaturierter Form aus, während die Nucleinsäure und andere Abspaltungsprodukte in Lösung bleiben. Die $A$-Lösungen erwiesen sich als praktisch inaktiv bis auf $A$ III, die eine Wirksamkeit von 70 Einzelherden je 100 Blatthälften besaß. Die hiermit angestellten Versuche Nr. 5 und 8 zeigen dementsprechend eine höhere Aktivität, die aber die Summe der Wirksamkeit der $Z$ - und der $A$-Lösung nicht überschreitet.

begrenzten Empfindlichkeit des biologischen Testes nicht ausgeschlossen werden.

\section{Besprechung der Ergebnisse}

Wenn es auch nicht gelungen ist, ein biologisch aktives Virus aus den Spaltstücken wieder aufzubauen, so ist die Tatsache doch recht interessant, daß bei ihrer Wiedervereinigung zum mindesten ein physikalisch-chemisch sehr ähnliches Molekül entsteht. Man kann hieraus wohl den Schluß ziehen, daß die Molekülform des Virus vor andern möglichen Anordnungen der Untereinheiten energetisch bevorzugt ist.

Wir haben hier also ein eindrucksvolles Beispiel einer auswählenden Polymerisation vor uns, wie sie in der Natur, aber auch im Laboratorium, häufig beobachtet wird. Die Kräfte, die diese auswählende Polymerisation bewirken, sind noch unbekannt. Unsere in vitro durchgeführten Versuche zeigen jedenfalls, daß hierfür nicht spezifisch biologische Kräfte der Zelle verantw ortlich zu machen sind, wie sie kürzlich von G. V.S $\mathrm{ch} \mathrm{u} \mathrm{z}^{6}$ neben anderen Gründen in Erwägung gezogen wurden, um die auffallende Einheitlichkeit natürlicher Makromoleküle zu erklären.

Weiterhin läßt sich sagen, daß es sich nicht um ein einfaches Gleichgewicht handeln kann zwischen einer polymerisierenden und depolymerisierenden Kraft (etwa der Oberflächenspannung und kinetischen Energie), da sonst das gleichzeitige Auftreten mehrerer Maxima (siehe hierzu Abb. 3 u. 5) nicht zu verstehen ist.

Das Problem, warum bei der Polymerisation bestimmte Stufen bevorzugt sind, tritt uns bereits bei dem ersten von uns beobachteten Aggregationsschritt entgegen, nämlich bei dem Übergang des Teilchens vom Mol.-Gew. 120000 in ein solches mit 360000 . Wegen der Zunahme des Reibungskoeffizienten bei dem Aggregationsprodukt

5 S. Koller, Graphische Tafeln zur Beurteilung statistischer Zahlen. Th. Steinkopff, Dresden u. Leipzig 1943.

${ }_{6}^{6}$ G. V. S c h u l z, Z. Naturforschg. 1, 268 [1946]. 
müssen wir hier eine lineare Anlagerung annehmen $^{1}$. Es ist schwer einzusehen, warum diese gerade bei der Bildung einer Dreiergruppe abbricht. Da dieser Prozeß einheitlich verläuft und übersichtlich ist, wäre hier ein geeigneter Ansatzpunkt gegeben, um das Problem der auswählenden Polymerisation experimentell näher $\mathrm{zu}$ bearbeiten.

Für die Ausbildung der Polymerisationsstufen scheinen die Eigenschaften der Grundeinheiten maßgeblich zu sein. Durch die Struktur der Untereinheit vom Mol.-Gew. 120000 ist demnach die Gestalt des hochmolekularen Virusproteins bereits weitgehend bestimmt. Dies legt die Vermutung nahe, daß diese Untereinheit auch bei der biologischen Entstehung des Virus eine beherrschende Funktion einnimmt. Tatsächlich erscheint es nicht ausgeschlossen, daß die Virusentstehung über eine solche Untereinheit verläuft.

Gegen diese Annahme scheint zunächst zu sprechen, daß kleinere vermehrungsfähige Moleküle als das hochmolekulare Virus bisher nicht nachgewiesen werden konnten. So zeigte $\mathrm{L}$ a uffe $\mathrm{r}^{7}$ durch Ultrazentrifugierungs-Versuche an Viruspräparaten, die durch Ultrazentrifugierung gereinigt waren, daß die Aktivität nahezu vollständig an die hochmolekulare Komponente gebunden ist. Allerdings konnte er nicht ausschließen, daß für einen sehr geringen Teil der Wirksamkeit ein niedrigmolekularer Träger in Frage kommt. Diese

7 M. A. L a u f f e r, J. biol. Chemistry 151, 627 [1943].

8 H. Friedrich-Freksa, G. Melchers u. G. S c h r a m m , Biol. Zbl. 65, 188 [1946].
Ergebnisse sind jedoch kein entscheidender Einwand gegen unsere Annahme, da wirksame niedrigmolekulare Proteine durch die vorhergehende Reinigung vielleicht schon entfernt waren oder vermehrungsfähige Untereinheiten im Plasma nicht beständig sind, weil sie nahezu vollständig zu dem hochmolekularen, in diesem Fall ebenfalls vermehrungsfähigen Proteins aggregieren.

Für die Annahme vermehrungsfähiger Untereinheiten spricht ein Befund, der in anderem $\mathrm{Zu}$ sammenhang veröffentlicht wurde ${ }^{8}$. Es zeigte sich nämlich nach einer von $\mathrm{H}$. Friedrich-Freksa durchgeführten serologischen Untersuchung, daß bei der Mutation des TMV wahrscheinlich alle Untereinheiten gleichartig verändert werden. Dieser Befund ist am einfachsten zu verstehen, wenn man eine solche Untereinheit als Zwischenstufe bei der Virusentstehung annimmt, ihnen also eine Vermehrungsfähigkeit zuschreibt. Andernfalls wäre man gezwungen, ein gleichzeitiges „Umklappen" aller Untereinheiten bei der Mutation anzunehmen, was recht schwer vorzustellen ist. Es wird vielleicht möglich sein, durch die Übertragung der hier beschriebenen Experimente auf die Mutanten des $T M V$ diese Frage einer weiteren Klärung zuzuführen.

Die chemischen und physikalischen Untersuchungen im 1. und 2. Teil dieser Arbeit wurden unter Mithilfe von Frl. L. R e be n sburg und Frl. H. S cha a r w ä c h t e r durchgeführt. Hrn. Dr. B e r g o ld danke ich für die Durchführung der Diffusionsmessungen. Frl. Wo elf f e r sind wir für die unter der Leitung von Dr. G. M e l c h e r s durchgeführten Testversuche zu Dank verpflichtet. 